\title{
EFFECT OF KAYAKING ON BALANCING ABILITY AFTER SUDDEN CHANGES IN DIRECTION
}

Árpád László Németh, Rita M. Kiss, Petra Aradi

Cooperation Research Center for Biomechanics

nemetharpi89@gmail.com

\section{Abstract \\ Introduction}

Different sports influence the balancing ability variously. The aim of this study to examine the effect of kayaking on dynamical balancing ability after sudden changes in direction.

\section{Methods}

The investigation included 5 race-kayakists and 5 leisure-time sportsmen. Dynamical balancing ability have analyzed by the ultrasound-based sudden perturbation test (provocation test). A rigid platform have moved from its central position and fixed by a fastening unit. The rigid platform connected to a rigid frame by 4 or 8 steel springs of identical strength. The platform swings back into its original, resting position, stimulating sudden disturbances after releasing the fastening unit. The participant must balance and re-equilibrate as the plate moves. The motions of the rigid plate were recorded by an ultrasound-based system. From this motion the Lehr's damping ratio can be calculated and it characterizes the balancing ability of the investigated person.

\section{Results}

For the kayakist group, the average values of the Lehr's damping ratio determined were significantly bigger while standing on one limb and on both limbs compared to the parameters for the control group.

\section{Discussion}

A high level of complex coordination is required to regain equilibrium after a sudden change in direction. Sports activities can develop this ability. This investigation demonstrate that not only the traditional methods (a sudden stoppage from running, sudden setting in motion, jumping or changing in direction) but motion in a continuously moving media (in aqueous media) can also develop the balancing ability. During kayaking the media always changes; moreover, it often surges so persistent balancing is essential. The results draw attention to the fact that dynamic balancing ability can be developed by other than traditional methods.

Keywords: kayak, athletes, equilibrium ability after unidirectional sudden perturbation

\section{Introduction}

The maintenance of balance is generally necessary during most motions, ranging from daily activities to more complex sport movements. The process of balancing can be realized if most parts of the body are in accordance. For example, we use more than 200 muscles of the 650 muscles of the body during walking., ${ }^{8,11}$ Postural control is a complex function combining sensory input, centralized processing and neuromuscular responses. ${ }^{15}$ 
Most studies of postural control have focused on measuring balance during quiet standing. Postural balance has been characterized by different types of parameters such as COP (centre of pressure) or COM (centre of mass) posture and other parameters derived from studies on postural sway during standing., ${ }^{5,-19}$

But static balance tests cannot sufficiently describe the maintenance of balance in daily activities (for example during walking). ${ }^{20}$ During gait or when an external perturbation affects balance control, the risk of falling can occur. ${ }^{12}$ There are studies that have analysed balance responses during walking on a walkway ${ }^{13}$ and on a treadmill at a self-selected speed. ${ }^{6}$ Few studies have examined the effect of sinusoidal moving platform translation on postural movement and stability. ${ }^{1-4}$ These studies have examined the linear motion of body segments and the movement of COP or COM, and postural control and postural sway have been characterized by COP or COM parameters. ${ }^{20}$

A high level of complex coordination is required to regain equilibrium after a sudden impulse or a change in direction. This phenomenon often occurs in everyday life when one is hit or jerked while standing or walking. ${ }^{20}$ These types of effects cannot be modelled using the traditional measurement methods.

Regaining the equilibrium after a sudden impulse or changes in direction can be measured using a provocation test. Balancing capacity can be characterized by the Lehr's damping ratio. Only a few research studies have been produced using this method up to the present. Two groups (a group of healthy young and healthy elderly participants) were examined, and then the results were compared. The reliability of the provocation test is demonstrated because the test was repeated with both patient groups after 7 weeks. There were no significant differences between the measurements. The other important result of this study is that the body mass of the investigated person does not influence the Lehr's damping ratio.

The provocation test required the most complex balancing capacity. The above-mentioned studies did not deal with the effect of sports on balancing capacity. This study discusses the effect of kayaking on balancing capacity. A comparison is made between two groups of 5 people each; one of them consists of race-kayakists and the other group is a control group with nonsportsmen. Efficient balance control during kayaking is of primary importance. Therefore, kayaking is a suitable sport to explore the difference in balancing between sportsmen and nonsportsmen.

\section{Methods}

\subsection{Participants}

The investigation included 5 healthy leisure-time sportsmen, with similar physical abilities: they constituted the control group. The control group was compared with a group of 5 race-kayakists, signed racers of UTE Kayak-Canoe section. Table 1 provides the demographic features of the participants. 


\begin{tabular}{|c|c|c|c|c|}
\hline $\begin{array}{c}\text { CONTROL } \\
\text { GROUP }\end{array}$ & $\begin{array}{c}\text { Age } \\
\text { (years) }\end{array}$ & $\begin{array}{l}\text { Height } \\
\text { (m) }\end{array}$ & $\begin{array}{l}\text { Mass } \\
(\mathrm{kg})\end{array}$ & $\begin{array}{c}\mathrm{BMI} \\
\left(\mathrm{kg} / \mathrm{m}^{2}\right)\end{array}$ \\
\hline Control 1 & 23 & 1.76 & 71 & 22.92 \\
\hline Control 2 & 23 & 1.76 & 75 & 24.21 \\
\hline Control 3 & 22 & 1.73 & 66 & 22.05 \\
\hline Control 4 & 21 & 1.83 & 68 & 20.31 \\
\hline Control 5 & 22 & 1.78 & 76 & 23.99 \\
\hline Average & 22.2 & 1.77 & 71.2 & 22.70 \\
\hline Deviation & 0.84 & 0.04 & 4.32 & 1.59 \\
\hline Minimum & 21 & 1.73 & 66 & 20.31 \\
\hline Maximum & 23 & 1.83 & 76 & 24.21 \\
\hline $\begin{array}{c}\text { KAYAKIST } \\
\text { GROUP }\end{array}$ & $\begin{array}{c}\text { Age } \\
\text { (years) }\end{array}$ & $\begin{array}{l}\text { Height } \\
\text { (m) }\end{array}$ & $\begin{array}{l}\text { Mass } \\
(\mathrm{kg})\end{array}$ & $\begin{array}{c}\mathrm{BMI} \\
\left(\mathrm{kg} / \mathrm{m}^{2}\right)\end{array}$ \\
\hline Kayakist 1 & 19 & 1.87 & 84 & 24.02 \\
\hline Kayakist 2 & 23 & 1.79 & 75 & 23.41 \\
\hline Kayakist 3 & 22 & 1.88 & 72 & 20.37 \\
\hline Kayakist 4 & 22 & 1.75 & 76 & 24.81 \\
\hline Kayakist 5 & 19 & 1.93 & 78 & 20.94 \\
\hline Average & 21 & 1.84 & 77 & 22.71 \\
\hline Deviation & 1.87 & 0.07 & 4.47 & 1.95 \\
\hline Minimum & 19 & 1.75 & 72 & 20.37 \\
\hline Maximum & 23 & 1.93 & 84 & 24.82 \\
\hline
\end{tabular}

Table 1.Demographic data of subjects

There were no significant differences in age and height between the participants.

According to a physical examination performed before the test, the participants were not limited in their everyday motion and sports activities. Each participant's motion range, joint stability, axial position, muscular strength and muscular tension in the lower limbs were physiologically adequate.

Each participant was informed in writing about the risks and benefits of the study and given the opportunity to withdraw from the study at any time, and each of the participants provided signed consent. The study was authorized by the National Science and Research Ethics Committee $(174 / 2005)$.

\subsection{Methods}

The effect of sudden impulse or changes in direction can be modelled using a commercially available PosturoMed device. The PosturoMed (Haider-Bioswing, Weiden, Germany) device, with its moveable and adjustable unstable therapy plates, is a widely used training and therapy device for neuron-orthopaedic rehabilitation, sport rehabilitation, and the prevention of sports injuries in Europe. It has a rigid platform $(12 \mathrm{~kg}, 60 \mathrm{~cm} \times 60 \mathrm{~cm}$ ) (Figure 1a.) connected to a rigid frame by eight $15-\mathrm{cm}$ steel springs of identical strength (Figure 1b.). ${ }^{8,11}$ 
The displacement characteristic of the platform can be regulated by changing the number of working springs $(4,6$ or 8). When the fastening unit (provocation unit) is locked the device can be fixed (Figure 1c.). The plate can be moved from the central position in a wide range of translation (generally by $20 \mathrm{~mm}$ ) and can be fixed in different positions by the fastening unit. By releasing the unit, the rigid plate can be set into motion. The platform swings back into its original, resting position, stimulating sudden disturbances. The participant must balance and reequilibrate as the plate moves. In that case, the human body has to stop the oscillating platform, so the balancing ability of the investigated object is a damping element. The oscillating platform with the subject on it is a damped system. The short name for this test is provocation test.

a

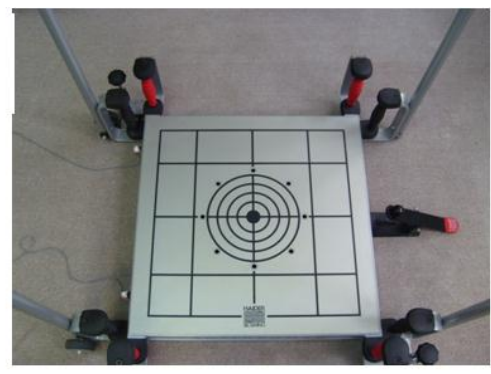

$c$

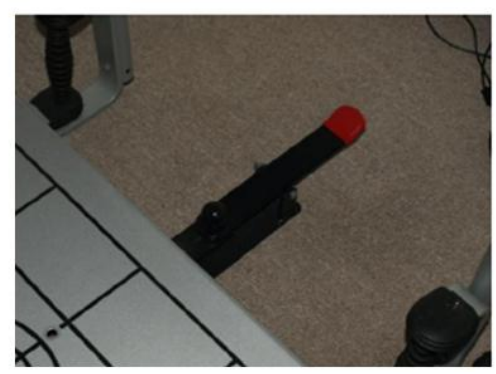

$b$

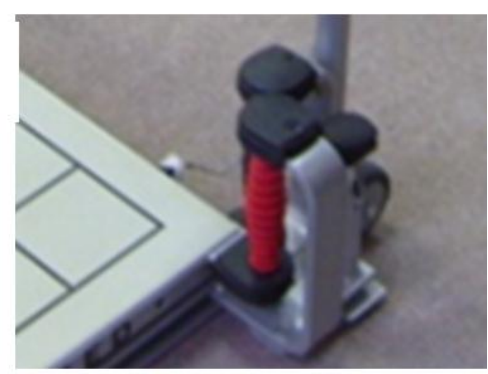

$d$

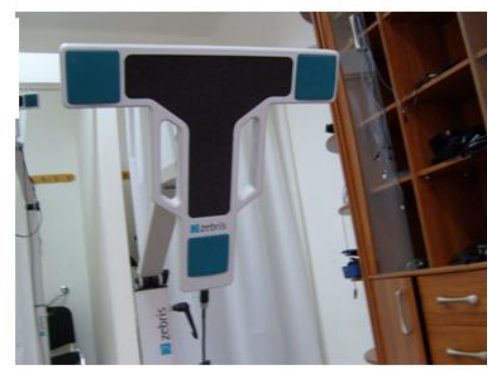

Figure 1. Measurement system components. (a) PosturoMed plate. (b) Steel spring. (c) Fastening unit. (d)Ultrasound-based measuring head.

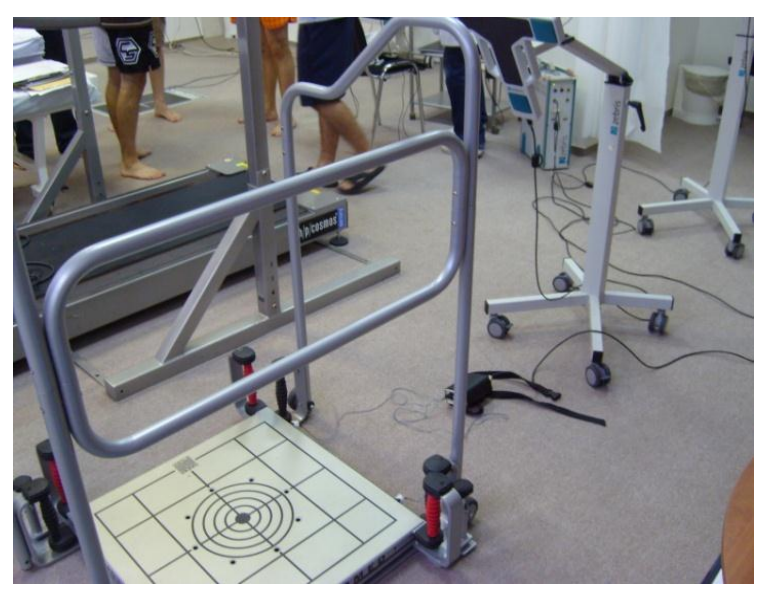

Figure 2. Measurement arrangement. Posturomed plate secured by springs of identical strength in different directions. Ultrasound-based measuring head located to the side of the object at 30 degrees.

In this study the test included four separate measurements: standing on both limbs, on the right and on the left limb and in a seated position (in a position similar to kayaking) (Figures $3 a, b$, and $c$, d). 
During the test, the motions of the rigid plate were recorded by single, individual markers attached on the side of the plate. The spatial coordinates of the markers were measured using a ZEBRIS CMS10 (Zebris, Medizintechnik GmbH, Germany) computer-controlled, ultrasoundbased motion analysis system (Figure 1d.). ${ }^{8} 11$ The measuring methods have been detailed in Kiss et al. ${ }^{10}$ The ultrasound-based measuring head was located to the side of the object at 30 degrees (Figure 2.), and the measuring frequency was $100 \mathrm{~Hz}$. The accuracy of the measuring system is less than $1 \mathrm{~mm}$. The tests were performed at the Biomechanical Laboratory of MÁV Hospital at Szolnok.

The participants were instructed that instead of watching their movement they should try to look straight ahead. Furthermore, they were instructed to balance with arm motion. They received no warnings that the plate would shift. If a participant did stumble or hold onto anything the trial was rejected.

The participants stood on the PosturoMed platform during the instructions to get acquainted with the unsteady platform. Before the measurement, an unrecorded trial was conducted to familiarize the participants with the procedure.

The participants were standing barefoot in the double-leg stance on the platform and during this time the platform was moved $20 \mathrm{~mm}$ in a medio-lateral direction towards the dominant side, and then locked by the fastening unit. After releasing the fastening unit the participants had to take up the standardized measuring position for $2 \mathrm{~s}$, and manage to counterbalance the sudden disturbance using compensatory equilibrium reactions.

Each shift (double-leg stance, both single-leg stances and seated position) was repeated three times. The first measurement was carried out at double-leg stance, followed by measurement at dominant leg stance, then at non-dominant leg stance and finally while sitting.

a

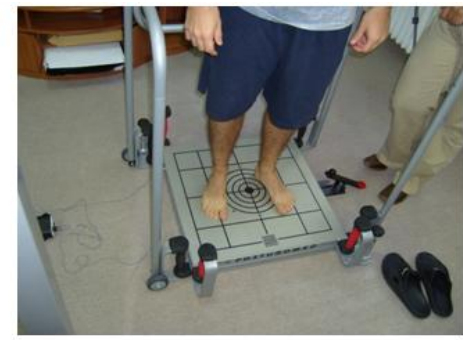

$c$

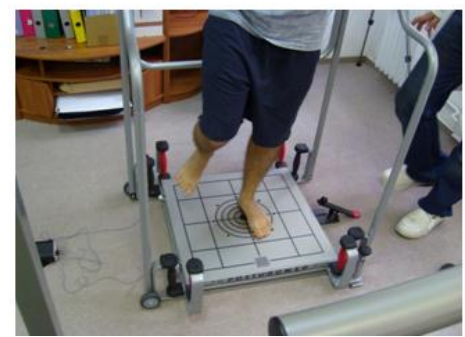

$b$
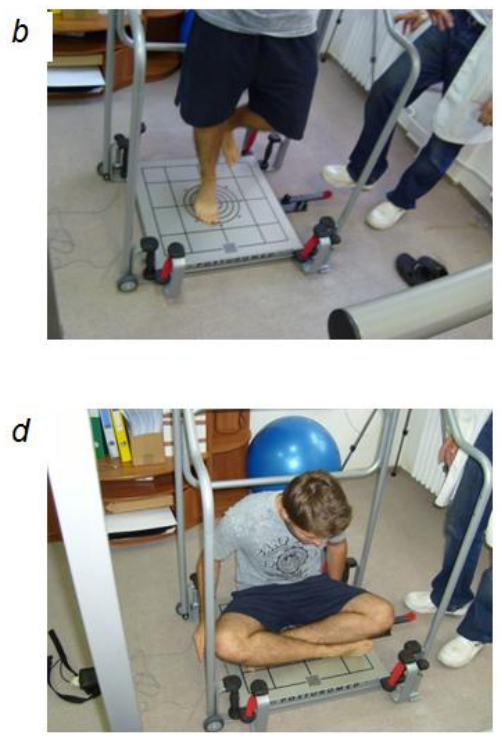

Figure 3. The four separate measurement positions. (a) Standing on both limbs. (b) Standing on the dominant limb. (c) Standing on the non-dominant limb. (d) Sitting stance. 
There were $60 \mathrm{~s}$ rest intervals between measurements. The average values of successfully completed trials were taken as the value for each measuring position; a minimum of two successfully completed trials were required for each measuring position.

\subsection{Assessment parameters ${ }^{8-9,10,12}$}

The oscillating PosturoMed device with the participant on it is a damped system. The differential equation of the damped system is as follows (Figure 4.). ${ }^{7-9,11}$

$$
\ddot{x}(t)+\frac{k}{m} \dot{x}(t)+\frac{1}{m c} x(t)=0
$$

where: $\quad \mathrm{m}[\mathrm{kg}=\mathrm{Ns} 2 / \mathrm{m}]$ is the mass of the participant and the platform,

$\mathrm{k}[\mathrm{Ns} / \mathrm{m}]$ is the damping value,

$\mathrm{c}[\mathrm{m} / \mathrm{N}]$ is the spring constant of the PosturoMed device.

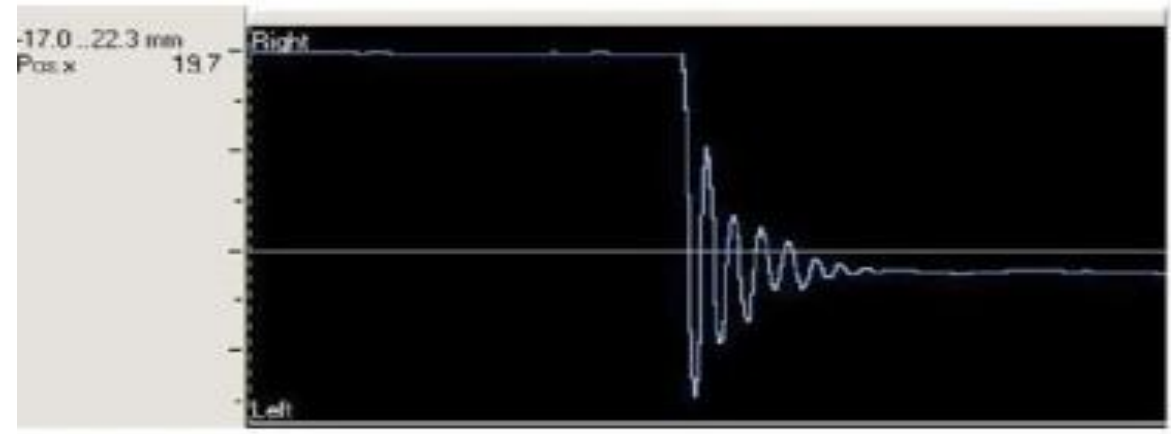

Figure 4. Damping curve_1. Lateral displacement of the measuring plate calculated from the spatial coordinates of the markers. The coordinate $\mathrm{x}$ is parallel to the direction of provocation and shows a damping curve.

From the above-mentioned damping curve the following parameters can be calculated:

- Average logarithmic decrement

During the test the logarithmic decrement is not exactly constant by reason of the many disturbing factors and because of the fact that the system is not closed. It is useful to determine the average logarithmic decrement - which is the average of the natural logarithm of the ratio of the amplitudes in an identical direction - for two periods separate in time (Figure 5.):

$$
\Lambda_{i}=\frac{1}{i-1} \ln \frac{K_{1}}{K_{i}}
$$

where: $\quad \mathrm{K}_{1}$ is the amplitude at moment $\mathrm{t}=\mathrm{t}_{1}$,

$K_{i}$ is the amplitude at moment $t=t_{i}$. 


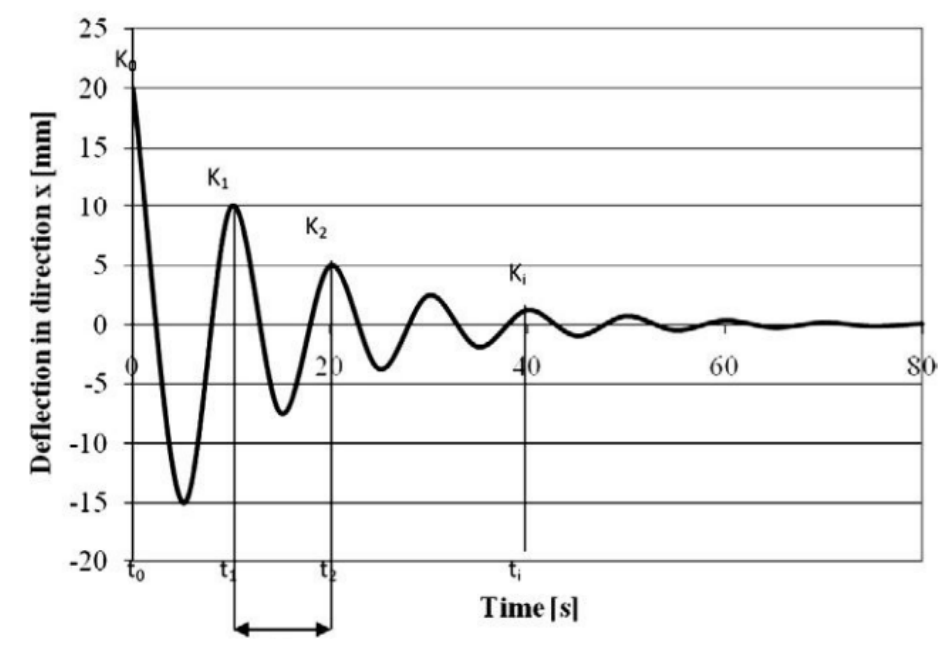

Figure 5. Damping curve_2. Factors required to determine swing parameters ( $\mathrm{K}_{\mathrm{i}}$ is the amplitude at moment $\mathrm{t}=\mathrm{t}_{\mathrm{i}}, \mathrm{T}$ is the swing time). [8,9,11]

- The Lehr's damping ratio

Using the logarithmic decrement the Lehr's damping ratio can be calculated, which is the ratio of actual and critical damping:

$$
D=\frac{\Lambda}{\sqrt{\Lambda^{2}+4 \pi^{2}}}
$$

If $\mathrm{D}>1$, the damping is too large, there will be no oscillating motion.

If $\mathrm{D}=1$, the system will have critical damping, and return to its equilibrium position.

If $0<\mathrm{D}<1$, the motion is damped.

If $\mathrm{D}=0$, the result is undamped oscillation.

The measurement of balancing capacity in a static posture (standing, sitting) or during motion (walking, running) after a sudden perturbation such as a jump, sudden stop or sudden change in direction is a new, experimental method for motion analysis. The provocation test models the standing balance after a sudden change in direction. After a sudden perturbation the human posture manages to return to its original, stable state. The recovery of equilibrium depends on the balancing ability of the subject, which means that the muscles need to be activated to a certain extent. The functions of the muscles include producing force, controlling the body mass, and damping the oscillating plate. In this investigation the damping value was used to characterize the balancing ability.

If $\mathrm{D}=1$ (critical damping), then the system returns to its stable position immediately without oscillation, which represents a perfect balancing ability. If $\mathrm{D}=0$, then the subject cannot damp the system. The Lehr's damping ratio (D) characterizes the actual damping ability in the ratio of the perfect damping value. It can be stated that the Lehr's damping ratio characterizes the balancing ability. Furthermore, higher values of D means larger damping, so in this case the balancing ability is also better. 


\subsection{Statistical analysis}

Lehr's damping ratios of the investigated groups were statistically analyzed using MS Excel Analysis Tool Pak Software.

The averages and standard deviations were calculated. The normality of the data distribution was assessed using the Kolmogorov-Smirnov test, and the uniformity of the standard deviations was assessed using an F-test.

The differences between the average values of identical parameters were determined by a onesample t-test, applying a symmetrical critical range on the two-leg and right-leg, on the two-leg and left-leg and lastly on the dominant and opposite sides. In addition, a two-sample t-test applying a symmetrical critical range was conducted on the different groups. The significance level was $\mathrm{p}<0,05$. $^{7,14}$

\section{Results}

Each volunteer managed to complete all four parts of the test; thus no exclusions occurred for incomplete results. The Lehr's damping ratio was between 0 and 1 so in all cases, the motion of the rigid plate was a damping movement. Table 2 provides the results of the test.

For both groups, there was no significant difference between the average values of the Lehr's damping ratio determined while standing on both limbs compared to the parameters determined while standing on the dominant $\operatorname{limb}$ (control group: $\mathrm{p}=0.085786321$, kayakist group: $\mathrm{p}=0.358633728)$.

For both groups, the average values of the Lehr's damping ratio determined while standing on the non-dominant limb were significantly smaller compared to the parameters determined while standing on both limbs (control group: $\mathrm{p}=4.33692 \mathrm{E}-05$, kayakist group: $\mathrm{p}=0.013274122$ ).

For the control group, the average values of the Lehr's damping ratio determined while standing on the non-dominant limb was significantly smaller compared to the parameters determined while standing on the dominant limb $(\mathrm{p}=0.018143081)$.

For the kayakist group, there was no significant difference between the average values of the Lehr's damping ratio determined while standing on the non-dominant limb compared to the parameters determined while standing on the dominant $\operatorname{limb}(\mathrm{p}=0.270511876)$.

The average value of the Lehr's damping ratio determined while sitting was significantly smaller for the control group compared to the parameters for the kayakist group. (psitting $=0.030894465$ )

\begin{tabular}{|c|c|c|}
\hline \multicolumn{3}{|l|}{ Average results } \\
\hline & \begin{tabular}{|l} 
CONTROL \\
GROUP
\end{tabular} & $\begin{array}{l}\text { KAYAKIST } \\
\text { GROUP }\end{array}$ \\
\hline standing on both limbs & 0.058205168 & 0.054602563 \\
\hline standing on dominant limb & 0.046872176 & 0.048530459 \\
\hline standing on non- dominant limb & 0.017101718 & 0.0346371 \\
\hline sitting & 0.347739265 & 0.41046332 \\
\hline
\end{tabular}


Results of statistical analysis

\begin{tabular}{|l|l|l|}
\hline One-sample t-test & $\begin{array}{l}\text { CONTROL } \\
\text { GROUP }\end{array}$ & $\begin{array}{l}\text { KAYAKIST } \\
\text { GROUP }\end{array}$ \\
\hline $\begin{array}{l}\text { standing on both limbs and standing on } \\
\text { dominant limb }\end{array}$ & 0.085786321 & 0.358633728 \\
\hline $\begin{array}{l}\text { standing on both limbs and standing on } \\
\text { non-dominant limbs }\end{array}$ & $\mathbf{4 . 3 3 6 9 2 E - 0 5}$ & $\mathbf{0 . 0 1 3 2 7 4 1 2 2}$ \\
\hline $\begin{array}{l}\text { standing on dominant limb and standing on } \\
\text { non-dominant limb }\end{array}$ & $\mathbf{0 . 0 1 8 1 4 3 0 8 1}$ & 0.270511876 \\
\hline
\end{tabular}

\begin{tabular}{|l|l|}
\hline Two-sample t-test & \\
\hline standing on both limbs & 0.336123346 \\
\hline standing on dominant limb & 0.456813202 \\
\hline standing on non- dominant limb & 0.218101272 \\
\hline sitting & $\mathbf{0 . 0 3 0 8 9 4 4 6 5}$ \\
\hline
\end{tabular}

Table 2. Lehr's damping ratio (D) calculated from the results of the provocation test (mean $\pm \mathrm{SD})$

\section{Discussion}

To summarize the innovation of this study compared to former motion analysis, the following statements can be made. First of all, the dynamic balancing ability of active sportsmen was measured by a provocation test. The provocation test was formerly used to examine the effect of aging $^{7}$ and the effect of degree of hip osteoarthritis on balancing ability. ${ }^{9}$ This study deals with the difference of balancing ability between healthy young people and sportsmen and the fact that sports can improve this ability. Furthermore, the other new element of the study was that the sportsmen were examined in a special posture. The kayakists were examined seated, which is a position they get accustomed to in the course of their everyday training.

The following observations can be stated by the comparison of the average Lehr's damping ratio of the two groups. The two groups performed approximately equally while the participants were standing on both limbs and on the dominant limb. The kayakist group had better results while standing on the non-dominant limb and while sitting. It is perceptible that the kayakist subjects possess similar Lehr's damping ratios for their dominant and non-dominant limbs, respectively, whereas the damping ratio of the non-dominant limbs of the members of the other group is three times worse than the damping ratio of their dominant limbs.

Regarding the results of comparisons within the same group, the Lehr's damping ratio calculated during standing on both limbs did not differ significantly from the value calculated during standing on the dominant limb for either of the groups. However, the results calculated during standing on both limbs did differ significantly from the calculated during standing on the nondominant limb. In short, equilibrium after a sudden change in direction was similar when standing on both limbs and on the dominant limb, but it was decreased during standing on the non-dominant limb. Consequently it can be stated that in general, equilibrium ability after a 
sudden change in direction is significally influenced by the equilibrium ability of the dominant side.

Another new finding from the current research is that the Lehr's damping ratio calculated during standing on the non-dominant limb compared to the value calculated during standing on the dominant limb was significantly smaller in the control group but surprisingly, there was no significant difference in the kayakist group. The result of the control group was prospective and it confirms the findings of former research studies. ${ }^{7,9}$ However, it was not expected that there would be no significant difference between the equilibrium ability of the dominant and the nondominant limb in the kayakist group. Therefore, there is no dependence on lateral dominance in case of the kayakists.

Regarding the results of comparisons between the different groups, the average value of the Lehr's damping ratio determined while sitting was significantly smaller for the control group compared to the parameters of the kayakist group. So it is reasonable to assume that the balancing ability of kayakists is significantly better in the special position they become accustomed to. Measurements while seated were unusual for the participants of the control group, but this special circumstance was not unknown for the kayakists because they grew familiar with it during their trainings.

A high level of complex coordination is required to regain equilibrium after a sudden change in direction. Sports activities can develop this ability. This investigation demonstrated that not only the traditional methods (a sudden stoppage from running, sudden setting in motion, jumping or changing in direction) but motion in a continuously moving media (in aqueous media) can also develop the balancing ability. During kayaking the media always changes; moreover, it often surges so persistent balancing is essential.

In summary, the results of the provocation test prove that unique balancing ability can be gained during motion in continuously changing, dynamic circumstances. The results draw attention to the fact that dynamic balancing ability can be developed by other than traditional methods.

\section{REFERENCES}

1. Berger W, Discher M, Trippel M, Ibrahim IK, Dietz V. Developmental aspects of stance regulation, comprehension and adaption. Experimental Brain Research 1992;90:610-9.

2. Buchanan JJ, Horak FB. Emergence of postural pattern as a function of vision and translation frequency. Journal of Neurophysiology 1999;91:2325-39.

3. Corna S, Tarantola J, Nardone A, Giordano A, Schiepati M. Standing on a continuously moving platform: is body inertia counteracted or exploited? Experimental Brain Research 1999;124:331-41.

4. Dietz V, Trippel M, Ibrahm IK, Berger W. Human stance on a sinusoidally translating platform: balance control by feed forward and feedback mechanism. Experimental Brain Research 1993;93:35662.

5. Donker SF, Roerding M, Greven AJ, Beek FJ. Regularity of centre of pressure trajectories depends on the amount of attention invested in postural control. Experimental Brain Research 2007;181:1-11. 
6. Hof AL, Vermerris SM, Gjalterna WA. Balance responses to lateral perturbation in human treadmill walking. Journal of Experimental Biology 2010;213:2655-64.

7. Kiss RM. A new parameter for characterizing balancing ability on an unstable oscillatory platform. Medical Engineering \& Physics 2011;33:1160-6.

8. Kiss RM. Biomechanics - Analysis of motion E-note for biomedical engineer students. Budapest: 2010. p. 153-8,227-43.

9. Kiss RM. Effect of the degree of hip osteoarthritis on equilibrium ability after sudden changes in direction. Journal of Electromyography and Kinesiology 2010;20:1052-7.

10. Kiss RM, Kocsis L, Knoll Zs. Joint kinematics and spatial temporal parameters of gait measured by an ultrasound based system. Medical Engineering \& Physics 2004;26:611-20.

11. Kocsis L, Kiss RM, Illyés Á. Biomechanics of organs of locomotion. Budapest: TERC 2007. p. 138-40, 147-50,197-214.

12. Liu W, Kim SH, Long JT, Pohl PS, Duncan PW. Anticipatory postural adjustments and the latency of compensatory stepping reaction in humans. Neuroscience Letters 2003;336:1-4.

13. Majewski M, Bishoff-Ferrari HA, Gruneberg C, Dick W, Allum JHJ. Improvements in balance after total hip replacement. The Journal of Bone and Joint Surgery British 2005;87B:1337-43.

14. Nádori L, Derzsy B, Fábián Gy, Osváth K, Rigler E, Zsidegh M. Measuring of sport ability. Budapest: Editor Sport 1989. p. 60-85.

15. Nashner LM. Computerized dynamic posturography. In: Goebek JA, editor. Practical management of Dizzy patients. Philadelphia: Lippicott Williams and Wilkins; 2001.

16. Newell KM, van Emmerik REA, Lee D, Sparague RL. On postural stability and variability. Gait and posture 1993. p. 1:225-30.

17. Prieto TY, Myklebust JB, Hoffmann RG, Lovett EG, Myklebust Bm. Measures of postural steadiness: differences between healthy young and elderly adults. IEEE Transaction on Biomedical Engineering 1996;43:956-66.

18. Riley MA, Balasubramaniam R, Turvay MT. Recurrence quantification analysis of postural fluctuation. Gait and Posture 1999;9:65-78.

19. Yamada N. Chaotic swaying of the upright posture. Human Movement Science 1995;14:711-36.

20. Winter DA. ABC of balance during satnding and walking. Waterloo: Waterloo Biomechanics; 1995.

Special thanks to Professor Kiss for her advice and help and to Petra Aradi MD PhD and Maria Takács $M D$ for their assistance in completing the measurements.

The authors gratefully acknowledge the Hungarian Scientific Research Fund OTKA for providing financial support in the frame of the grant $K-083650$. 